\title{
THE PREVALENCE OF VISUAL DEFECT AMONG COMMERCIAL VEHICLE DRIVERS IN SELANGOR, MALAYSIA
}

\author{
Victor Hoe CW \\ Department of Social and Preventive Medicine, Faculty of Medicine, University of Malaya, 50603 Kuala Lumpur, Malaysia
}

\begin{abstract}
A cross-sectional survey of commercial vehicle drivers who were renewing their own licences was conducted at the Selangor Road Transport Department office in Padang Jawa between 1 February 2002 and 28 February 2002, using questionnaire and medical examination. The objective was to determine the prevalence of myopia, colour vision deficiency and visual field defect among the commercial vehicle drivers. The respondents that reported visual defect at the time of interview was compared with those detected by the author through medical examination. Out of the 223 respondents, $21(9.4 \%)$ reported to have myopia by the questionnaire survey. Through the visual examination there were $63(28.3 \%$ ) with myopia (visual acuity worse than $6 / 12$ ), six $(2.6 \%)$ had a visual field defect and $14(6.3 \%)$ had red-green colour deficiency. The visual defect detected during the study among the commercial vehicle drivers, which were missed at the time of the routine medical examination were significant. The process of the statutory medical examination should be reviewed. (JUMMEC 2006; 9(1): 35-38)
\end{abstract}

KEYWORDS: Medical examination, myopia and driving, commercial vehicle drivers, visual acuity

\section{Introduction}

Road accidents have been emerging as one of the leading cause of fatalities in the world today. In 1998, it was the tenth Leading Cause of Death; causing more than one million fatalities (I). The World Health Organization has forecast that, by the year 2020, road accidents will be the second most common cause of premature death in the world (I).

In Malaysia, road traffic injuries were responsible for $45.8 \%$ of hospitalization and $68.9 \%$ of injury deaths in government hospitals. Every day about 15 people die on the road (2).

Commercial vehicle drivers spend a lot of time on the roads. Some of them have to operate large and long vehicles, which are more difficult to manoeuvre during stopping, acceleration, and lane changing, and difficult in judgement of clearance for both height and length. These vehicles will have a greater potential for damage and injury in cases of road accidents.

The reasons for road traffic accidents can broadly be divided into three; those related to the road user, vehicle design and road environment $(3,4)$. The factors that are related to the road user include those due to the drivers and pedestrians. The drivers' factors are annual mileage, fatigue and inattention, age, intoxication and speeding (5).

Many medical conditions, including vision impairment had been associated with road traffic accidents $(6,7,8$, $9,10,11,12$, ). Vision plays a very important role in safe driving, it is often said that approximately $90 \%$ to $95 \%(13,14)$ of the sensory input to the brain required for driving comes from vision. With this much at stake that is why visual acuity had been a key issue in the issuing of driving licences in many countries.

\section{Vision requirement for driving}

Different countries have different visual standards for private and commercial vehicle drivers $(15,16,17$,

Corresponding Address:

Dr. Victor Hoe Chee Wai

Department of Social and Preventive Medicine

Faculty of Medicine, University of Malaya

50603 Kuala Lumpur

Malaysia 
$18,19)$. In this study the author only looked at factors that had been established by the Road Transport Department (RTD) of Malaysia, which included visual acuity for distant visual defect (myopia), colour vision and visual field (20).

All drivers in Malaysia are required to possess a valid driving licence in its class. There is no prior medical examination for driving private vehicles; the drivers are only required to read the licence plates test and colour plates during the learners' licence test. Commercial vehicles drivers would have to undergo annual medical screening before they are allowed to renew their vocational licences. Medical practitioners registered with the Malaysian Medical Council (MMC) perform this medical screening after which they will have to endorse the JPJ L8A form from RTD stating that the driver is medically fit to drive commercial vehicles.

The visual acuity requirements stated in the guideline from RTD, are minimum of 6/60 in each eye without glasses and $6 / 12$ or better in each eye with corrective glasses. Commercial vehicle drivers who need corrective glasses for driving need to declare this in their driving licences. The other visual requirements are normal colour vision and a normal field of vision.

\section{Materials and Methods}

A cross-sectional descriptive study on the prevalence of myopia among the commercial vehicle drivers was conducted at the Selangor State RTD Office in Padang Jawa. Commercial vehicle drivers who were renewing their own vocational licences between I February 2002 and 28 February 2002 were selected as the study population. Those who were applying for new licences were excluded. The interview and the vision examination were conducted by the author at the RTD office. The vision examinations included visual acuity examination using the Snellen Charts (alphabet or the illiterate $\mathrm{E}$ chart), colour vision using Ishihara Chart and visual field examination using the Humphrey Perimeter. Data management and analysis were done using the SPSS (Version 10.0).

\section{Results}

\section{Characteristics of respondents}

There were 223 drivers who responded to the questionnaire and the medical examinations. None of the drivers approached by the author refused to cooperate. All of the respondents were male. Their ethnic group distribution is shown in Table I.The mean age of the respondent was 36.3 years (SD 7.8) and range from 22 years to 58 years.
Table I. Ethnic group distribution of respondents

\begin{tabular}{lcc}
\hline Ethnic & Total & Percentage \\
\hline Malay & 138 & 61.9 \\
Chinese & 23 & 10.3 \\
Indian & 51 & 22.9 \\
Others* & 11 & 4.9 \\
\hline Total & 223 & 100 \\
\hline
\end{tabular}

* The others stated in the table included 8 Indonesians, one Kadazan, one Kampuchean, and one Pakistani. All the respondents were Malaysian nationals.

\section{Statutory medical screening}

Out of the 223 respondents, seven (3.1\%) reported that their medical screening was not carried out, and their doctors had only endorsed the RTD medical forms.

\section{Previous medical conditions}

Out of the 223 respondents, six $(2.7 \%)$ were known to suffer from diabetes mellitus; five were on oral medications and one on sub-cutaneous insulin injection. Seven (3.1\%) had hypertension and were on regular medication. None of the respondent reported to have either epilepsy or cardiovascular diseases.

Seven (3.1\%) had defective colour vision, 21 (9.4\%) had myopia and 14 (6.3\%) had presbiopia. Five of the respondents had pterygium and one had squint. None of the respondents has cataract or glaucoma. Out of the 21 respondents who were known to have myopia, only 14 were using their corrective glasses while driving.

\section{Medical examination}

During the medical examination the author detected 52 with visual acuity of worse than 6/12; for those that used corrective glasses, visual acuity tests were performed with their corrective glasses. Seventeen respondents had visual acuity of worse than 6/12 in the right eye alone and ten had visual acuity of worse than $6 / 12$ in the left eye alone. Twenty-five had visual acuity worse than 6/12 in both eyes. Two respondents had visual acuity of $6 / 60$ in the right eye and two respondents had visual acuity of $6 / 60$ in the left eye. One of the respondents had visual acuity of 6/60 in both eyes.

Out of the fourteen that used corrective glasses, three had visual acuity of worse than 6/12 in either one eye even with their corrective glasses. When comparing ethnicity and visual defect, the Chinese has the highest percentage of visual defect $(47.8 \%)$ compare to other races (Table 2 ), the result are comparable to other studies $(21,22,23)$. Six respondents $(2.6 \%)$ had a visual field defect and 14 (6.3\%) had red-green colour deficiency. 
Table 2. Race and visual defect

\begin{tabular}{lccccc}
\hline Visual & \multicolumn{4}{c}{ Race (percentage) } & Total \\
Defect* & Malay & Chinese & Indian & Others \\
\hline No & 106 & 12 & 36 & 6 & 158 \\
& $(76.8)$ & $(52.2)$ & $(70.6)$ & $(54.5)$ & $(71.7)$ \\
Yes & 32 & 11 & 15 & 5 & 63 \\
& $(23.2)$ & $(47.8)$ & $(29.4)$ & $(43.5)$ & $(28.3)$ \\
\hline Total & 138 & 23 & 51 & 11 & $\mathbf{2 2 3}$ \\
& $(100)$ & $(100)$ & $(100)$ & $(100)$ & $(100)$
\end{tabular}

* Visual defect includes those who wear glasses as stated in questionnaire and has visual acuity of worse than $6 / / 2$.

\section{Adequacy of statutory medical examination}

The author used visual acuity as an indicator for adequacy for statutory medical examination. Comparing the prevalence of reported myopia and the results of visual acuity examination, taking visual defect to be worse than 6/12. When people with myopia who used corrective glasses were excluded from the results, the author found that there is a significant difference between the result of the visual acuity examination and the reported myopia (Table 3 ). The medical examination revealed 49 of the respondents with visual acuity worst than 6/12 and five respondents who had visual acuity of $6 / 60$ were missed during the statutory medical screening. This indicated that the statutory medical examination had failed to detect a significant number of drivers who had myopia.

Table 3. Myopia (from statutory medical screening) and visual defect* detected by examination

\begin{tabular}{lccc}
\hline Myopia & \multicolumn{3}{c}{ Visual Acuity } \\
& No & $\begin{array}{c}\text { Defect } \\
\text { Yes }\end{array}$ & Total \\
\hline No & 157 & 45 & 202 \\
Yes & 3 & 4 & $7^{\#}$ \\
\hline Total & 160 & 49 & 209
\end{tabular}

Measurement of Agreement:

Kappa 0.089, Std Error $=0.057$, Sig $=0.032$

* Visual acuity defect is taken as visual acuity worst than 6//2 when reading the Snellen chart at 20 feet (six meter).

\# The 14 individuals with myopia and wear corrective glasses have been excluded from the findings.

\section{Discussion}

A total of 223 drivers were interviewed; their ages were between 22 and 58, with the majority less than 40 year old.

\section{Myopia}

In this study, the author found 63 (28.3\%) drivers with myopia. This includes the 14 who wore corrective glasses. Of those who wore corrective glasses, II had visual acuity of $6 / 12$ or better with the corrective glasses and three had visual acuity worse than $6 / 12$. The result is comparable to the study done on young males in Singapore, which is $30.4 \%$ (23), but in another study on I 10,236 Singaporean males, the percentage is higher at $44.2 \%(24)$.

\section{Statutory medical examination}

The results of this study showed that the statutory medical examination had failed to detect a significant number of drivers with myopia and other visual defects. The statutory medical examination also missed a driver with insulin-dependent diabetes mellitus, which should have been disqualified under the RTD guidelines and JPJ L8A (20) forms.

The above result showed that although statutory medical examinations were required for the commercial vehicle drivers, the medical examinations conducted were not up to the required standard. The examination failed to reveal diseases that were not allowed by law to drive commercial vehicles. This can be serious, as other studies have shown an association between such medical conditions and road accidents. One possible reason for the failure of the medical practitioner to conduct a more thorough medical examination may be due to the fact that fees for each medical examination was only between RM5 and RMI5 (US\$I = RM3.80), although a thorough medical examination would takes at least 20 minutes to conduct. The Malaysian Medical Council Fee Schedule 1997 recommended the fees for medical examination for commercial vehicle drivers to be RM50 (25). Another reason could be that the medical practitioner may not be aware of the minimum medical requirement for commercial vehicles drivers as the visual field test requirement was not stated clearly in the RTD guideline.

\section{Conclusion}

This study confirms that the prevalence of visual defect among the commercial vehicle drivers are similar to that of earlier studies on normal population within this region. It appears that many of the drivers are not aware of defects in their vision despite having undergone a thorough medical examination. Furthermore, those who were aware of their visual defect did not correct the defect, and were still driving with vision that do not meet the standard RTD requirements. 
The authority should look into this matter and revise the format and form of the statutory medical examination as this can be detrimental to the safety of road users.

\section{Acknowledgement}

The author wishes to thank Dr Ling Kin Hong for his advice and guidance in conducting this study, and is grateful to the Selangor Road Transport Department at Padang Jawa for their cooperation.

\section{References}

I. World Health Organization. Injury a leading cause of the global burden of disease. WHO Geneva, 1999.

2. Road Injuries, 20-27: Epidemiology of Injury in Malaysia 2nd Edition, Disease Control Division, Public Health Department, Ministry of Health Malaysia.

3. Sabey BE, Taylor H.The known risks we run: the highway. TRRL Supplementary Report SR 567. Crowthorne: TRL Ltd; 1980.

4. Carsten OMJ, Tight MR, Southwell MT. Urban road crashes: why do they happen? Report of a study on contributory factors in urban road traffic road crashes. University of Leeds, Institute of Transport Studies. AA Foundation for Road Safety Research, Basingstoke; 1989.

5. Road Accidents Impact on Insurers. Internet communication at http://www.piam.org.my/news/piamnews/ p005htm (accessed 2I Aug 200l).

6. Preboth M. Risk of driving in patients with alzheimer's disease. Am Fam Physician 200I; 63: 982-984

7. Horne J, Reyner L. Sleep-related vehicle road crashes. BMJ 1995; 310: 565-567

8. Young T, Blustein J, Finn L, et al. Sleep-disorder breathing and motor vehicle road crashes in a population-based sample of employed adults. Sleep 1997; 20: 608-6I3.

9. Strohl K, Bonnie R, Findley L, et al. Sleep apnea, sleepiness, and driving risk. Am J Respir Crit Care Med 1994; 150: | 463-73.

10. Westlake W. Another look at visual standards and driving. BMJ 2000; 321: 972-973.

II. Skipp MD. Potential human and economic cost-savings attributed to vision testing policies for driver licence renewal, I989-199I. Optom Vis Sci 1998; 75: I03-II8.
12. Johnson C, Keltner J. Incidence of field loss in 20,000 eyes and its relationship to driving performance. Arch Ophthalmol 1983; 101: 371-375.

13. Visual Standards for Driving. Internet communication at http://www.rcophth.ac.uk/publications/visual_standards. html (accessed 2 Jan 2002).

14. Driving and Mobility. Internet communication at http:// www.lighthouse.org/research-driving.htm (accessed 2 Jan 2002).

15. Visual acuity. Internet communication at http:// driverlicense.utah.gov/medical/pdf/il.pdf (accessed II Jan 2002).

16. Medical Standards. Internet communication at http:// nrtc.gov.au/publications/med-k.asp?lo=public (accessed II Jan 2002).

17. Driver and Vehicle Licencing Agency. At a Glance. Visual Disorders. Internet communication at http:// www.dvla.gov.uk/at_a_glance/ch6_visual.htm (accessed 12 Feb 2002).

18. U.S. Department of Transport. Federal Motor Carrier Safety Administrations. Regulation - Section 39l.4I (b) (10). Internet communication at http://www.fmcsa.dot. gov/rulesregs/fmcsr/regs/39l4I.htm (accessed 3 Sept 200I).

19. U.S. Department of Transport. Federal Motor Carrier Administration. Visual Requirements and Commercial Drivers. Internet communication at http://www.fmcsa. dot.gov/pdfs/visionfinalreport 10-16-98.pdf (accessed 13 Sept 200I).

20. Road Transport Department of Malaysia. Statutory medical examination JPJ L8A form.

2I. Tay MTH, Au Eong KG, Ng CY, et al. Myopia and education attainment in 421, I16 young Singaporean males. Ann Acad Med Singapore; 2 I (6): 785-79I.

22. Teoh GH, Yow CS. Prevalence of squints and visual defects in Malaysia primary one school children. Med J Malaysia; 37(4): 336-337.

23. Wilson A, Woo G.A review of the prevalence and causes of Myopia. Singapore Med J 1989; 30: 479-484.

24. Au Eong KG, Tay TH, Lim MK. Race culture and myopia in 1 10,236 Singapore males. Singapore Med J 1993; 34: 29-32

25. Malaysia Medical Association Fees Schedule, 1997. 